\title{
Inhibitors of the renin-angiotensin system: The potential role in the pathogenesis of COVID-19
}

\author{
Ziyin Huang*, Yufeng Jiang*, Jingjing Chen, Yafeng Zhou \\ Department of Cardiology, the First Affiliated Hospital of Soochow University, \\ Suzhou City, Jiangsu Province, P.R. China
}

\begin{abstract}
Coronavirus disease 2019 (COVID-19), which initially began in China, has spread to other countries of Asia, Europe, America, Africa and Oceania, with the number of confirmed cases and suspected cases increasing each day. According to recently published research, it was found that the majority of the severe cases were elderly, and many of them had at least one chronic disease, especially cardiovascular diseases. Angiotensin-converting enzyme inhibitors/angiotensin receptor blockers (ACEIs/ARBs) are the most widely used drugs for cardiovascular diseases. The clinical effect of ACEIs/ARBs on patients with COVID-19 is still uncertain. This paper describes their potential role in the pathogenesis of COVID-19, which may provide useful in the advice of cardiologists and physicians. (Cardiol J 2020; 27, 2: 171-174)
\end{abstract}

Key words: COVID-19, 2019-nCoV, renin-angiotensin system, angiotensin-converting enzyme inhibitors

\section{Introduction}

Since December 2019, a series of pneumonia cases of unknown etiology were reported in $\mathrm{Wu}-$ han, Hubei province, China. A novel coronavirus named 2019 novel coronavirus (2019-nCoV) was identified by the Chinese Center for Disease Control and Prevention (CDC) from the throat swab sample of a patient and the disease was subsequently officially named COVID-19 by the World Health Organization. As of March 20, 2020, more than 240,000 people have been confirmed with COVID-19 across the world. A pandemic of the novel coronavirus has posed significant threats to international health and the economy $[1,2]$.

$2019-\mathrm{nCoV}$ is the seventh coronavirus that has been confirmed to infect humans. It has $50 \%$ genomic similarity to the Middle East respiratory syndrome coronavirus (MERS-CoV), 75-80\% to the severe acute respiratory syndrome coronavi- rus (SARS-CoV) and 96\% to a coronavirus found in bats. $2019-\mathrm{nCoV}$ encodes at least 27 proteins, including 15 non-structural proteins, 4 structural proteins, and 8 auxiliary proteins. Spike glycoprotein $(\mathrm{S})$ which locates on the outer envelope of the virion is responsible for binding to the host receptor angiotensin-converting enzyme 2 (ACE2).

The majority of the severe patients diagnosed with COVID-19 were elderly. In a study of 52 severe, adult patients, researchers found that the mean age of these patients was 60 years and $40 \%$ of these patients had at least one chronic disease such as hypertension [3, 4]. Angiotensin-converting enzyme inhibitors/angiotensin receptor blockers (ACEIs/ARBs), which are the most widely used drugs for hypertension. But whether ACEIs/ARBs should be used in patients with COVID-19 is still a question worthy of discussion. This paper describes its potential role in the pathogenesis of COVID-19, which may provide useful advice for cardiologists and physicians.

Address for correspondence: Yafeng Zhou, PhD, Department of Cardiology, the First Affiliated Hospital of Soochow University, 188 Shizi Road, Suzhou City, 215006, P.R. China, tel: 86-512-67781726, fax: 86-512-67781712, e-mail: zhouyafeng73@126.com

Received: 31.03.2020 Accepted: 11.04.2020

*Ziyin Huang and Yufeng Jiang contributed equally to this work. 


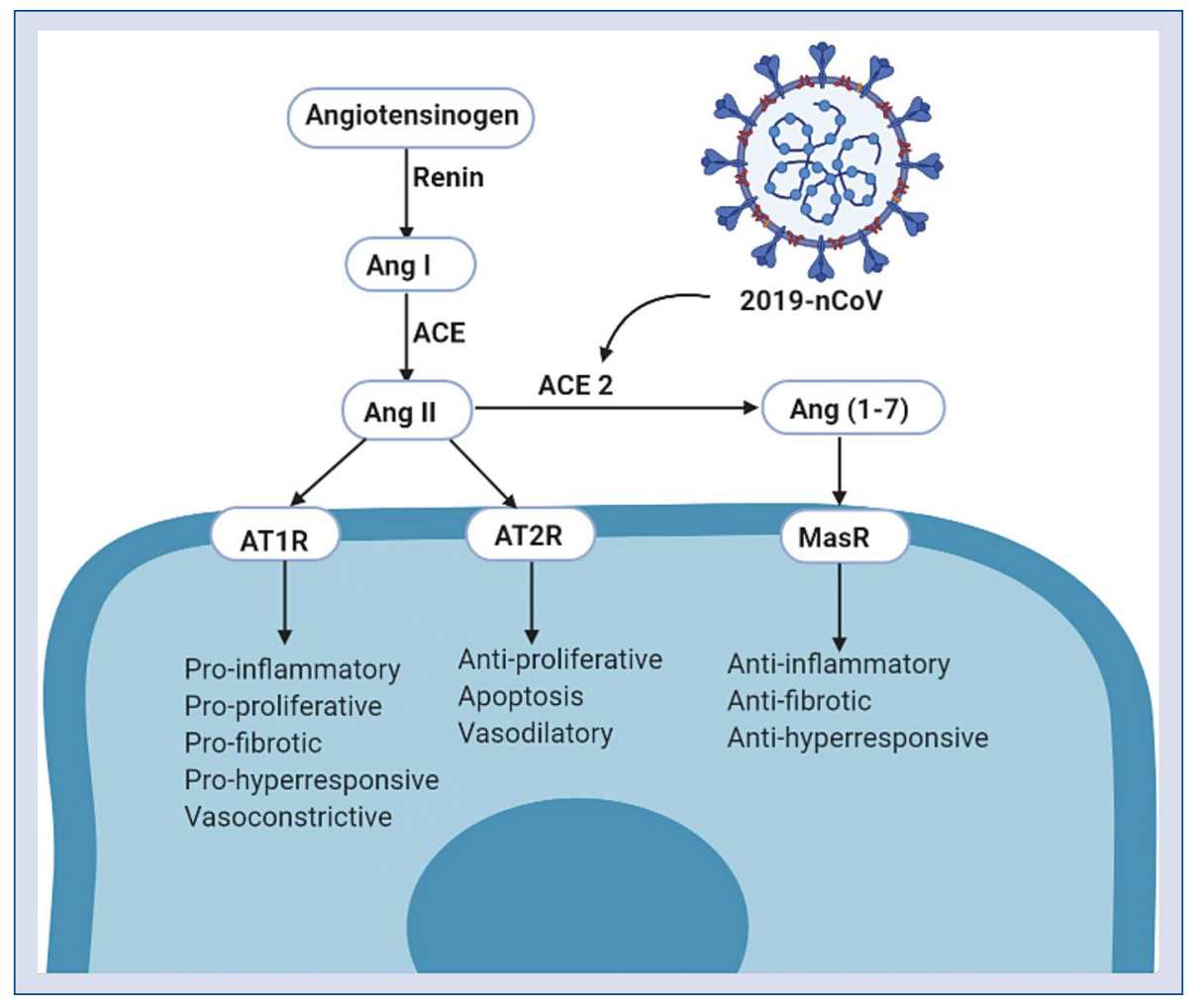

Figure 1. The renin-angiotensin system and 2019-nCoV.

\section{Renin-angiotensin system and multi-system inflammation}

Renin, a protease that is generated primarily in the kidney, cleaves angiotensinogen to generate angiotensin I (AngI). Subsequently, a protease called angiotensin-converting enzyme (ACE) cleaves AngI to produce angiotensin II (AngII). AngII is a key effector of the renin-angiotensin system (RAS) and exerts biological functions through two receptors: AngII receptor type 1 $\left(\mathrm{AT}_{1} \mathrm{R}\right)$ and $\mathrm{AngII}$ receptor type $2\left(\mathrm{AT}_{2} \mathrm{R}\right) . \mathrm{AT}_{1} \mathrm{R}$ is coupled to $\mathrm{G}$ protein-coupled receptor which can stimulate multiple signaling path-ways including tyrosine kinases, MAPK/ERK, Rho/ROCK kinase and PLC $\beta / \mathrm{IP} 3 /$ diacylglycerol. $\mathrm{AT}_{1} \mathrm{R}$ activation mediates catecholamine release from peripheral sympathetic neurons, inflammation via NF-kB activation, ROS production through NADH/NADPH oxidese activity, apoptosis via toll-like receptor 4 activation and lung fibroblast proliferation. ACE2, a homologue of $\mathrm{ACE}$, is responsible for producing Ang(1-7) by cleaving AngII. Ang(1-7) binds and activates $\mathrm{G}$ protein-coupled Mas receptor to exert anti-inflammatory and anti-remodeling effects [5-7]. ACE2 is abundantly present in the epithelia of the lung and small intestine. It was also present in most arterial and venous endothelial cells and arterial smooth muscle cells [8-10]. In a study published recently, researchers found that the distribution of ACE2 is more widespread in males than in females: at least 5 different types of cells in the male lung express this receptor, while only $2 \sim 4$ types of cells in female lungs express the receptor. The ACE2/Ang(1-7)/Mas receptor pathway often serves to counter-regulate the pro-inflammatory, pro-fibrotic and pro-hyperresponsive effects of the $\mathrm{ACE} / \mathrm{AngII} / \mathrm{AT}_{1}$ receptor pathway. The imbalance between $\mathrm{ACE} / \mathrm{AngII} / \mathrm{AT}_{1}$ receptor pathway and ACE2/Ang(1-7)/Mas receptor pathway in the RAS will lead to multi-system inflammation (Fig. 1). And increased ACE and AngII are poor prognostic factors for severe pneumonia [11, 12].

Activation of the ACE2/Ang(1-7)/Mas receptor pathway is also proven to play a possible role in cardio-protection. Ferreira firstly put forward that low concentrations of ANG-(1-7) produced a significant reduction of ischemia/reperfusion induced cardiac arrhythmias in isolated rat hearts. In addition to influencing cardiac rhythm, ANG-(1-7) has a significant anti-remodeling effect in different models of cardiomyopathy. It may be concluded that 
an increased level of ANG-(1-7) may prevent heart dysfunction, inhibit oxidative stress, protect against cardiac hypertrophy, and attenuate left ventricular remodeling. Not only in the respiratory and cardiovascular system, but also anti-inflammatory effects of ACE2/Ang(1-7)/Mas receptor pathway in kidney, liver, central nervous system, endocrine system, and others have also been successively confirmed [13].

\section{Renin-angiotensin system and COVID-19}

2019-nCoV infects people via the Spike-ACE2 binding pathway $[14,15]$. The binding of 2019-nCoV and ACE2 resulted in the exhaustion of ACE2 and then ACE2/Ang(1-7)/Mas receptor pathway was inhibited. The inhibition of this system may lead to many pathophysiological changes. In an animal trial published in "Nature", it showed that loss of ACE2 expression precipitated severe lung injury. They also performed a rescue experiment by using recombinant human ACE2 protein (rhuACE2). The results showed that injection of rhuACE2 into acid-treated ACE2 knockout mice decreased the degree of acute lung injury which is assessed by lung elastance and pulmonary edema formation. When they injected rhuACE2 protein into acid-treated wild-type mice, lung function and edema formation were also rescued [16-18].

Of note, demonstrated herein, was that serum AngII level were extremely elevated in COVID-19 patients. More importantly, plasma AngII levels were linked to disease severity and predicted a fatal outcome in these patients. To test whether Spike-Fc injections indeed affect the function of the RAS, researchers analyzed AngII levels in the lungs of Spike-Fc-treated mice. Notably, a significant increase was observed in AngII levels in the lung tissue of these mice. To further confirm whether Spike-Fc promotes lung disease pathogenesis through increased AngII, they blocked the $\mathrm{AT}_{1} \mathrm{R}$ with a specific inhibitor. The results showed that inhibition of the $\mathrm{AT}_{1} \mathrm{R}$ indeed attenuated acute severe lung injury and pulmonary edema in these mice $[19,20]$. Taken together, it is concluded that $2019-\mathrm{nCoV}$ can exaggerate acute lung failure through deregulation of the $\mathrm{ACE} / \mathrm{AngII} / \mathrm{AT}_{1}$ receptor pathway. Moreover, 2019-nCoV Spike-mediated lung failure can be rescued by the inhibition of $\mathrm{AT}_{1} \mathrm{R}$.

\section{ACEIs/ARBs and COVID-19}

According to the reasons described below, it may speculated that ACEIs/ARBs could be used in patients with COVID-19 to reduce the multi-system inflammation response and mortality by decreasing AngII level. But some researchers have proposed a different point of view. What is known is that 2019-nCoV infects patients by the binding receptor ACE2. Use of ACEIs/ARBs may contribute to an increased level of ACE2 which makes the virus more likely to invade cells $[21,22]$. Some scientists have suggested using ACE2 inhibitor called N-(2-aminoethyl)-1 aziridine-ethanamine to block the 2019-nCoV spike protein-mediated cell fusion [23].

ACEIs/ARBs reduces the multi-system inflammation response in patients with COVID-19. But it also provides the virus with more receptors. The clinical effect it brings needs prospective studies and clinical trials to confirm this. Some scientists have suggested that the most rapid approach for assessing its feasibility is to analyze clinical patient records to determine whether COVID-19 patients who were medicated with $\mathrm{AT}_{1} \mathrm{R}$ antagonists prior to their diagnosis had better disease outcome. If COVID-19 patients medicated with $\mathrm{AT}_{1} \mathrm{R}$ antagonists have reduced pulmonary inflammatory response and lower mortality, this would support the notion that ACEIs/ /ARBs confer protection from severe symptoms among 2019-nCoV infected individuals. Knowledge gained from such datamining of clinical records may prove that ACEIs/ARBs provides positive clinical effect evidence for COVID-19 patients [24].

\section{Conclusions}

ACEIs/ARBs might be an attractive therapeutic agent to treat COVID-19 patients with cardiovascular diseases by reducing the pulmonary inflammatory response. The fact that increased levels of ACE2 may provide $2019-\mathrm{nCoV}$ with more receptors and make it easier to invade cells should not be ignored. More prospective studies and randomized clinical trials are needed to prove its clinical effect on COVID-19 patients.

\section{Acknowledgements}

This work was supported by grants from National Natural Science Foundation of China (81873486), Natural Scientific Fund of Jiangsu province (BK20161226), Jiangsu Province's Key Provincial Talents Program (ZDRCA2016043), Jiangsu Province's 333 High-Level Talents Project (BRA2017539). The funders had no roles in the study design, data collection or analysis, neither a decision to publish, or preparation of the manuscript.

Conflict of interest: None declared 


\section{References}

1. Velavan TP, Meyer CG. The COVID-19 epidemic. Trop Med Int Health. 2020; 25(3): 278-280, doi: 10.1111/tmi.13383, indexed in Pubmed: 32052514.

2. Habibzadeh P, Stoneman EK. The novel coronavirus: a bird's eye view. Int J Occup Environ Med. 2020; 11(2): 65-71, doi: 10.15171/ijoem.2020.1921, indexed in Pubmed: 32020915.

3. Arabi YM, Murthy S, Webb S, et al. COVID-19: a novel coronavirus and a novel challenge for critical care. Intensive Care Med. 2020 [Epub ahead of print], doi: 10.1007/s00134-020-05955-1, indexed in Pubmed: 32125458.

4. Huang C, Wang Y, Li X, et al. Clinical features of patients infected with 2019 novel coronavirus in Wuhan, China. Lancet. 2020; 395(10223): 497-506, doi: 10.1016/S0140-6736(20)30183-5, indexed in Pubmed: 31986264.

5. Tan WS, Liao W, Zhou S, et al. Targeting the renin-angiotensin system as novel therapeutic strategy for pulmonary diseases. Curr Opin Pharmacol. 2018; 40: 9-17, doi: 10.1016/j. coph.2017.12.002, indexed in Pubmed: 29288933.

6. Kurtz A. Control of renin synthesis and secretion. Am J Hypertens. 2012; 25(8): 839-847, doi: 10.1038/ajh.2011.246, indexed in Pubmed: 22237158.

7. Balakumar P, Jagadeesh G. A century old renin-angiotensin system still grows with endless possibilities: AT1 receptor signaling cascades in cardiovascular physiopathology. Cell Signal. 2014; 26(10): 2147-2160, doi: 10.1016/j.cellsig.2014.06.011, indexed in Pubmed: 25007996.

8. Zhao Y, Zhao ZX, Wang YJ, et al. Single-cell RNA expression profiling of ACE2, the putative receptor of Wuhan 2019-nCov. BioRxiv. 2020, doi: 10.1101/2020.01.26.91985.

9. Fan C, Li K, Ding Y, et al. ACE2 expression in kidney and testis may cause kidney and testis damage after 2019-nCov infection. MedRxiv. 2020, doi: 10.1101/2020.02.12.20022418.

10. Hamming I, Timens W, Bulthuis MLC, et al. Tissue distribution of ACE2 protein, the functional receptor for SARS coronavirus. A first step in understanding SARS pathogenesis. J Pathol. 2004; 203(2): 631-637, doi: 10.1002/path.1570, indexed in Pubmed: 15141377.

11. Kaparianos A, Argyropoulou E. Local renin-angiotensin II systems, angiotensin-converting enzyme and its homologue ACE2: their potential role in the pathogenesis of chronic obstructive pulmonary diseases, pulmonary hypertension and acute respiratory distress syndrome. Curr Med Chem. 2011; 18(23): 3506-3515, doi: 10.2174/092986711796642562, indexed in Pubmed: 21756232.

12. Imai Y, Kuba K, Penninger JM. The discovery of angiotensin-converting enzyme 2 and its role in acute lung injury in mice.
Exp Physiol. 2008; 93(5): 543-548, doi: 10.1113/expphysiol.2007.040048, indexed in Pubmed: 18448662.

13. Santos RA, Sampaio WO, Alzamora AC, et al. The ACE2/angiotensin-(1-7)/MAS axis of the renin-angiotensin system: focus on angiotensin-(1-7). Physiol Rev. 2018; 98(1): 505-553, doi: 10.1152/physrev.00023.2016, indexed in Pubmed: 29351514.

14. Song W, Gui M, Wang X, et al. Cryo-EM structure of the SARS coronavirus spike glycoprotein in complex with its host cell receptor ACE2. PLoS Pathog. 2018; 14(8): e1007236, doi: 10.1371/ journal.ppat.1007236, indexed in Pubmed: 30102747.

15. Liu Z, Xiao X, Wei X, et al. Composition and divergence of coronavirus spike proteins and host ACE2 receptors predict potential intermediate hosts of SARS-CoV-2. J Med Virol. 2020 [Epub ahead of print], doi: 10.1002/jmv.25726, indexed in Pubmed: 32100877.

16. Imai $\mathrm{Y}$, Kuba $\mathrm{K}$, Rao $\mathrm{S}$, et al. Angiotensin-converting enzyme 2 protects from severe acute lung failure. Nature. 2005; 436(7047): 112-116, doi: 10.1038/nature03712, indexed in Pubmed: 16001071.

17. Imai Y, Kuba K, Penninger JM. [Lessons from SARS: a new potential therapy for acute respiratory distress syndrome (ARDS) with angiotensin converting enzyme 2 (ACE2)]. Masui. 2008; 57(3): 302-310, indexed in Pubmed: 18340998.

18. Khan A, Benthin C, Zeno B, et al. A pilot clinical trial of recombinant human angiotensin-converting enzyme 2 in acute respiratory distress syndrome. Crit Care. 2017; 21(1): 234, doi: 10.1186/ /s13054-017-1823-x, indexed in Pubmed: 28877748.

19. Kuba K, Imai Y, Rao S, et al. A crucial role of angiotensin converting enzyme 2 (ACE2) in SARS coronavirus-induced lung injury. Nat Med. 2005; 11(8): 875-879, doi: 10.1038/nm1267, indexed in Pubmed: 16007097.

20. Crackower MA, Sarao R, Oudit GY, et al. Angiotensin-converting enzyme 2 is an essential regulator of heart function. Nature. 2002; 417(6891): 822-828, doi: 10.1038/nature00786, indexed in Pubmed: 12075344.

21. $\mathrm{Xu} \mathrm{X,} \mathrm{Chen} \mathrm{P,} \mathrm{Wang} \mathrm{J,} \mathrm{et} \mathrm{al.} \mathrm{Evolution} \mathrm{of} \mathrm{the} \mathrm{novel} \mathrm{coronavirus} \mathrm{from}$ the ongoing Wuhan outbreak and modeling of its spike protein for risk of human transmission. Sci China Life Sci. 2020; 63(3): 457-460, doi: 10.1007/s11427-020-1637-5, indexed in Pubmed: 32009228.

22. Wevers BA, van der Hoek L. Renin-angiotensin system in human coronavirus pathogenesis. Future Virol. 2010; 5(2): 145-161, doi: 10.2217/fvl.10.4, indexed in Pubmed: 32201502.

23. Huentelman MJ, Zubcevic J, Hernández Prada JA, et al. Structure-based discovery of a novel angiotensin-converting enzyme 2 inhibitor. Hypertension. 2004; 44(6): 903-906, doi: 10.1161/01. HYP.0000146120.29648.36, indexed in Pubmed: 15492138.

24. Gurwitz D. Angiotensin receptor blockers as tentative SARS-CoV-2 therapeutics. Drug Dev Res. 2020 [Epub ahead of print], doi: 10.1002/ddr.21656, indexed in Pubmed: 32129518. 